\title{
Health visitors' awareness and perception of clinical genetic services
}

\author{
Penny Guilbert, Francine Cheater
}

\begin{abstract}
A questionnaire was sent to 84 health visitors to assess their awareness and perception of genetic services and how they perceived their role in the referral of patients. The study showed that while health visitors had a reasonable knowledge of the more obvious aspects of genetic services, there were a number of areas in which they were unsure. The respondents did not identify themselves as prime initiators in the process of referring patients to a genetic service, although they appeared able to identify families on their caseloads for whom this service may be relevant. Health visitors viewed their own knowledge of genetics as poor, a factor which may account for the low referral rate initiated by this group of professionals. The respondents attached importance to genetic issues and $76(95 \%)$ wished to be better informed about the subject. It is suggested that the inclusion of genetics as part of an in-service training programme might fulfil this need and lead to greater advocacy of genetic services among the families in their care.

These findings are of interest in view of the proposals within the recent Royal College of Physicians report (Prenatal screening and genetic counselling) suggesting that community genetic services should make use of primary health care workers such as health visitors.
\end{abstract}

It has been recognised for some time that, as morbidity and mortality owing to other causes are reduced, genetic disorders comprise a considerable proportion of the total burden of community disease in the United Kingdom. During the 1970s there was

Trent Sub-Regional Genetic Service, City Hospital, Hucknall Road, Nottingham NG5 1PB.

P Guilbert

Department of Nursing Studies, School of Medicine, Nottingham University Hospital, Nottingham.

F Cheater

Correspondence to Ms Guilbert.

Received for publication 3 January 1990.

Revised version accepted for publication 2 April 1990. increasing evidence that the provision of comprehensive clinical genetic services gave an opportunity for disease prevention, ${ }^{1}$ and, equally importantly, that such services could ensure that families can make informed reproductive decisions. It has been acknowledged that a significant number of people who may benefit from such services are not referred. ${ }^{2}$

Any attempt to reduce the incidence and burden of genetic disease is dependent upon the identification, screening, and counselling of those at risk. As with most preventive health care facilities, their success depends upon public awareness, understanding, and acceptance obtained through informed discussion and consent. ${ }^{3}$ The level of public awareness and acceptance is to some extent influenced by the knowledge and attitudes of primary health care professionals with whom they are in contact. It is important, therefore, that health care professionals, both in hospital and in the community, have an understanding of the basic principles of genetics, are aware of the services available, and are prepared to advocate their use by those of their clients who may benefit from them. Holtzman $^{4}$ stated that many health care providers, both doctors and nurses, have insufficient background knowledge of human genetics. Inadequate knowledge, it has been claimed, may present a barrier to the referral and receipt of optimal genetic services for the families concerned. ${ }^{56} \mathrm{~A}$ recent report by the Royal College of Physicians of London, Prenatal diagnosis and genetic screening, ${ }^{7}$ has examined the current provision of these services and found them to be imperfectly delivered, depriving many couples at risk of information and choice. This report recommends that screening and counselling services should be available to the community as a whole, but particularly as a component of maternal and child health services, in order to facilitate informed choice in reproductive decision making. As well as the specialist clinical genetic services, it recommends a complementary, coordinated, community genetic service for the implementation of population screening programmes and provision of information and counselling about some of the simpler issues. The report identified the need for adequate training of primary health care personnel to allow them to participate effectively in the provision of community genetic services. 
We could find no other study relating to health visitors' awareness and perception of genetic services; several studies among medical and nursing professionals, mainly in North America, have looked at similar issues. ${ }^{8-11}$ Young $^{12}$ and Shickle and May ${ }^{13}$ reported similar findings from studies undertaken in the United Kingdom. Most of these studies aimed to measure knowledge of genetics and attitudes to and use of genetic services. Their results suggested a relationship between knowledge of genetics and referral behaviour, with those well informed being more inclined to discuss such issues with their patients and to refer them to a specialist service where necessary. A number of studies have drawn attention to the need for improvement in the quantity and quality of teaching of genetics if professionals are to acquire a sufficiently detailed knowledge base to allow them to perform adequately in their practice settings. ${ }^{14-16}$

A recent study undertaken in one district health authority looked at health visitors' awareness and perception of clinical genetics services and the part played by this group of primary health care professionals in ensuring that genetic services reach those to whom it is relevant.

\section{Research method}

Permission was obtained from the Director of Community Clinical Services to approach health visitors working for the Nottingham District Health Authority. A Sub-Regional Clinical Genetic Service has been available in Nottingham for 17 years; counselling and diagnostic facilities are currently provided by a consultant clinical geneticist, two other medical staff, and three nurse specialists, with the support of cytogenetic and molecular laboratories. A sample was drawn from 20 health centres and comprised 84 health visitors. A questionnaire was designed consisting of 28 closed and open ended questions arranged in four sections. The first two parts collected demographic and educational data. Section three included questions about the health visitors' knowledge and use of the genetic service, and the final section included questions relating to the number of families on the health visitors' caseload for whom a genetic evaluation might be appropriate. They were also asked how they perceived their role in families with genetic disorders.

Questionnaires were delivered personally to the health visitors over a two week period in May 1989 and left for completion after an explanation of the study. A stamped addressed envelope was left for their return within a week.

\section{Results}

Eighty $(95 \%)$ of the sample responded. Demographic data showed an experienced group of health visitors of whom $42 \%$ had worked for the same health authority for more than 10 years.

\section{EDUCATION IN GENETICS}

Sixty $(75 \%)$ of the respondents reported having had some education in genetics, in some cases this would have been more than 10 years previously. Ninety-six percent of respondents endorsed the view that genetics should be included in health visitor training. In 26 (45\%) cases medical geneticists or genetic counsellors had participated in the course teaching and this was commented on as being particularly valuable. In addition, health visitors were asked how they kept up to date with issues involved in their work. Twenty three $(31 \%)$ had attended courses which included genetic information over the previous five years. When asked how well informed they felt about genetic issues, $65(.82 \%)$ stated they did not feel well informed and $76(95 \%)$ wished to be better informed. The topics upon which they wished to increase their knowledge are shown in table 1 . Of the 30 health visitors who responded to an invitation to make any other comments at the end of the questionnaire, 21 $(70 \%)$ mentioned the need for updating their knowledge about medical genetics and several suggested that this should include information about service provision as well as specific conditions.

KNOWLEDGE AND USE OF THE GENETIC SERVICE

Of the 79 health visitors who responded, 74 (94\%) stated that they were aware of the existence of a local clinical genetic service, but $14(18 \%)$ did not have a clear idea where this was located. When asked about

Table 1 Topics about which health visitors would like to be better informed $(n=76)$.

\begin{tabular}{lrr}
\hline Topic & No & $\%$ \\
\hline Screening for genetic disease & 64 & 85 \\
Prenatal diagnosis & 62 & 82 \\
Chromosome abnormality & 51 & 68 \\
Inheritance mechanisms & 51 & 68 \\
Other $^{*}$ & 5 & 6 \\
\hline
\end{tabular}

${ }^{*}$ Appropriate referral, syndromes, research.

Table 2 Reasons for contact with the clinical genetic service during last 12 months $(n=17)$.

\begin{tabular}{lr}
\hline Reason for contact & No \\
\hline Advice about referring family & 10 \\
Information after family attended & 7 \\
Information about a condition & 13 \\
Other: Self referral & 1 \\
\multicolumn{1}{c}{ To give information } & 1 \\
\hline
\end{tabular}


Table 3 Health visitors' perceptions of services offered to clients by a clinical genetic service.

\begin{tabular}{|c|c|c|c|c|}
\hline Statement & $\begin{array}{l}\text { Correct } \\
\text { response }\end{array}$ & No & Correct & Incorrect \\
\hline $\begin{array}{l}\text { Diagnosis of unusual condition, eg syndromes } \\
\text { Treatment of children with genetic disorder } \\
\text { Explanation of inheritance patterns } \\
\text { Discussion of recurrence risks } \\
\text { Screening and counselling of at risk relatives } \\
\text { Discussion of methods of avoiding an affected child } \\
\text { Prenatal screening options } \\
\text { Advise on whether to terminate a pregnancy } \\
\text { Counselling after termination for genetic abnormality } \\
\text { Bereavement counselling after loss owing to genetic disorder } \\
\text { Advise when couples should not have children } \\
\text { Effects of drugs/maternal illness upon fetus } \\
\text { Investigation of infertility/miscarriage } \\
\text { Correction of faulty genes } \\
\text { 'Genetic fingerprinting' paternity testing } \\
\text { Liaison with lay groups } \\
\text { Facilitate decision making within supportive relationship } \\
\text { Inform families of new information }\end{array}$ & $\begin{array}{l}\text { True } \\
\text { False } \\
\text { True } \\
\text { True } \\
\text { True } \\
\text { True } \\
\text { True } \\
\text { False } \\
\text { True } \\
\text { True } \\
\text { False } \\
\text { True } \\
\text { True } \\
\text { False } \\
\text { False } \\
\text { True } \\
\text { True } \\
\text { True }\end{array}$ & $\begin{array}{l}78 \\
77 \\
79 \\
78 \\
79 \\
78 \\
79 \\
73 \\
75 \\
75 \\
76 \\
77 \\
77 \\
74 \\
74 \\
76 \\
75 \\
77\end{array}$ & $\begin{array}{l}63(81 \%) \\
66(86 \%) \\
79(100 \%) \\
78(100 \%) \\
75(95 \%) \\
65(83 \%) \\
73(92 \%) \\
41(56 \%) \\
52(69 \%) \\
41(54 \%) \\
25(33 \%) \\
32(42 \%) \\
26(34 \%) \\
65(88 \%) \\
53(72 \%) \\
62(82 \%) \\
69(92 \%) \\
74(96 \%)\end{array}$ & $\begin{array}{c}15(19 \%) \\
11(14 \%) \\
- \\
- \\
4(5 \%) \\
13(17 \%) \\
6(8 \%) \\
32(44 \%) \\
23(31 \%) \\
34(46 \%) \\
51(67 \%) \\
45(58 \%) \\
51(66 \%) \\
9(12 \%) \\
21(28 \%) \\
14(18 \%) \\
6(8 \%) \\
3(4 \%)\end{array}$ \\
\hline
\end{tabular}

their use of the service, only $17(21 \%)$ health visitors had contacted the department in the last 12 months. The reasons for contact are shown in table 2. Eleven (14\%) of the health visitors had referred or initiated referral of a family to the service during that period; thus $68(85 \%)$ had not been active in obtaining genetic counselling for their clients. When asked who was the most appropriate professional to initiate discussion with a family about referral to a genetic service, 52 $(65 \%)$ of the respondents perceived this to be a medical responsibility and identified either the general practitioner or hospital consultant. Twelve (15\%) stated that initiation of such discussion should not be considered the role of any one professional, but rather it should be carried out by the most appropriate person in a given circumstance through negotiation with the client. Only $10(13 \%)$ of the health visitors identified themselves as the prime initiator of such discussion.

In order :o assess the health visitors' knowledge of the range of services offered by a clinical genetic service, respondents were asked to answer true or false to a series of 18 statements (table 3). Of the 79 respondents who completed all or some of the statements, more than two-thirds $(55,69 \%)$ had at least 13 of the 18 responses correct. The mean score was 13. This suggests that health visitors have a reasonably accurate knowledge of what is offered. It is important, however, to consider the items to which there were a high number of incorrect responses as these may represent aspects of the service about which health visitors are unclear. The large number of incorrect responses to questions about advice on whether to have children and when to terminate a pregnancy suggests that respondents do not have a correct perception of the non-directive role of the genetic counsellor.

\section{ROLE OF THE HEALTH VISITOR IN FAMILIES WITH} GENETIC DISORDER

Health visitors were asked to give the numbers of families on their caseloads with children under the age of 5 years and the numbers of these families who had a child with a developmental problem likely to have genetic implications. The figures obtained from these responses allowed an estimate to be made of the size of the population with recognised congenital abnormality for whom genetic evaluation might be appropriate. The estimated incidence in this population was $2 \cdot 8 \%$ which is very close to the generally quoted figure of $2.5 \%$ in the United Kingdom. This suggests that health visitors are aware of those families on their caseload with a potential genetic problem. However, fewer than a third of these families had, to their knowledge, had genetic counselling.

When asked what they considered their own role to be in families with known or suspected genetic disorder, the majority $(69,87 \%)$ included 'general support', particularly regarding management, and 36 $(45 \%)$ mentioned obtaining or clarifying information. Just over half $(41,52 \%)$ felt they should ensure referral to or liaison with other agencies including the clinical genetic service. This is in contrast to the results reported earlier where $13 \%$ of respondents reported that initiating discussion about referral was an appropriate role for the health visitor and the $14 \%$ of health visitors who had actually been active in securing referral for clients.

\section{Discussion}

The results indicate that health visitors were aware of most of the facilities offered by a genetic service. The misconceptions surrounding some of the services offered, however, suggest that health visitors may not 
be clear about the non-directive nature of genetic counselling and do not appreciate the full spectrum of involvement of a genetic service. This could affect the information being passed on to clients. It was disappointing to find the limited use made of the clinical genetic service as a resource, especially since the majority of health visitors perceived their role in families with genetic disorder to be supportive, offering counselling and advice and expanding information for the family.

The study indicated that health visitors did not identify themselves as prime initiators in the process of referring patients to a genetics service although they appeared able to identify families on their caseloads for whom such a service may be relevant. This finding is in contrast with most published reports about the role of the health visitor, which identifies referral activities as a key function. ${ }^{17-19}$ It is important to consider reasons for an apparent disparity between the health visitors' perception of their own role in ensuring referral of families to appropriate agencies, including the clinical genetic service, and their actual referral behaviour.

Several studies have linked the referral practices of health care professionals with their level of knowledge of genetics. 981112 The findings of these studies indicated that those who had attended recent basic or post basic courses in human genetics were more likely to refer patients to genetic services or screening programmes. The current study did not attempt to assess factual knowledge about genetics. The health visitors' perceived level of knowledge, however, indicated that $65(82 \%)$ did not feel well informed about the subject. The majority of respondents $(76$, $95 \%$ ) considered genetic issues to be important and wished to be better informed. This perceived lack of knowledge about genetics may be a factor inhibiting health visitors initiating discussion about such issues with their clients.

Nearly three-quarters of the respondents $(74 \%)$ had been in post for more than five years; therefore it was some time since they had trained. Less than a third $(23,31 \%)$ had attended study days, conferences, or courses during the last five years which had included genetic information. Many of the health visitors relied on journals to keep them up to date in most aspects of their work, but the most commonly read journals (The Health Visitor and Nursing Times) have had limited coverage of developments in genetics. ${ }^{20-22}$ These findings would suggest that some health visitors, who may have been in post for a considerable time, have had no education on genetic issues since their training. As Motulsky ${ }^{23}$ and others have suggested, health care professionals need to be acquainted with current realities in human genetics in order to ensure that clients are receiving correct information on which to base their decision making. In a time of rapid developments in the speciality health visitors may not be as up to date in their knowledge as perhaps they should be and this may make it difficult for them to fulfil adequately their own perceived role in families with genetic disorders. The majority of respondents (96\%) considered that genetic issues were important areas about which they should be informed and $28 \%$ identified the need for the provision of opportunities to update and extend their knowledge, perhaps as part of an in-service training programme.

Education in medical genetics and counselling techniques will be of even greater importance to primary health care professionals if families are to benefit from their involvement in community genetics services as proposed in the recent Royal College of Physicians report. $^{7}$

We would like to thank Dr J S Fitzsimmons, Sally Farnish, and colleagues in the Clinical Genetics Department, Nottingham, for their helpful comments and encouragement.

1 Fitzsimmons JS, Baraitser M, Davison BCC, et al. Report of the Clinical Genetics Society Working Party on regional genetics services. London: Eugenics Society: 1982, suppl 4.

2 Hall JG, Powers EK, McIlvaine RT. The frequency and financial burden of genetic disease in a pediatric hospital. Am 7 Med Genet 1978;1:417-36.

3 Rosenstock IM, Child B, Simopoulous AP. Knowledge, attitudes and behaviour. In: Genetic screening: programs, principles and research. Washington DC: National Academy of Sciences, 1975.

4 Holtzman NA. Recombinant DNA technology; genetic tests and public policy. Am f Hum Genet 1988;42:624-32.

5 Forsman I. Education of nurses in genetics. Am 7 Hum Genet 1988;43:552-8.

6 Cohen FL. Clinical genetics in nursing practice. Philadelphia: Lippincott, 1984.

7 Royal College of Physicians. Prenatal diagnosis and genetic screening. London: Royal College of Physicians, 1989.

8 Naylor E. Genetic screening and genetic counselling: knowledge, attitudes and practices in two groups of family planning professionals. Soc Biol 1975;22:304-14.

9 Weitz R. Barriers to acceptance of genetic counselling among primary health care physicians. Soc Biol 1979;26:189-97.

10 Cohen FL. Genetic knowledge possessed by American nurses and nursing students. $\mathcal{F}$ Adv Nurs 1979;4:493-501.

11 Williams JK. Pediatric nurse practitioners' knowledge of genetic disease. Pediatr Nurs 1983;9:119-21.

12 Young ID. Undergraduate teaching of genetics. Med Educ $1984 ; 18: 151-4$.

13 Shickle D, May A. Knowledge and perception of haemoglobinopathy carrier screening among general practitioners in Cardiff. f Med Genet 1989;26:109-12.

14 Mertens T, Hendrix J, Norris M. Nursing educators; perception of the curricular role of human genetics/bioethics. $\mathcal{F}$ Nurs Educ 1984;23:98-104.

15 Monsen RB. Genetics in basic nursing program curricula: a national survey. Maternal Child Nursing $\mathcal{f}$ 1984;13:177-85.

16 Davidson RG, Childs B. Perspectives in the teaching of human genetics. Ann Hum Genet 1984;2:79-119.

17 Council for Education and Training of Health Visitors. An investigation into the principles of health visiting in the United Kingdom. London: CETHV, 1977.

18 Health Visitors Association. The health visitor's role in child surveillance: a policy statement. London: HVA, 1985.

19 Luker KA, Chalmers KI. The referral process in health visiting. Int 7 Nurs Stud 1989;26:173-85.

20 Fitzsimmons E. Counselling for the future. Nursing Times 1985;81:22-4.

21 Guilbert PR, Jeavons B. Taking the risk. Nursing Times 1985;81: $25-7$.

22 Farnish S. All in the genes. Nursing Times 1986;82:53-5.

23 Motulsky A. Education needs of professionals. In Weiss J, Bernhardt B, Paul N, eds. Genetic disorders and birth defects in families and society. New York: Alan R Liss, 1984;20:15-37. 